\title{
Causal relationship testing with applications to exchange rates
}

\author{
T.J. Brailsford \\ UQ Business School \\ University of Queensland, Brisbane, Australia \\ E-mail: t.brailsford@business.uq.edu.au
}

\section{Jack Penm*}

School of Finance and Applied Statistics

The Australian National University, Canberra, Australia

E-mail: jack.penm@anu.edu.au

*Corresponding author

\section{R.D. Terrell}

National Graduate School of Management

The Australian National University, Canberra, Australia

E-mail: deane.terrell@anu.edu.au

\begin{abstract}
This paper undertakes two causality studies with exchange rate applications in a framework of Zero-Non-Zero (ZNZ) patterned Vector Error-Correction Modelling (VECM). The first study shows that money supply is a source of financial and economic influence on the Euro. The second gives evidence of support for Purchasing Power Parity (PPP) using monthly data between Japan and the USA. The results indicate that high-frequency finance data can reveal the existence of long-term PPP. This evidence sheds light on the adjustment mechanisms through which PPP is achieved. Also, the proposed ZNZ patterned VECM modelling allows better insights from this kind of financial time-series analysis.
\end{abstract}

Keywords: error correction models; e-finance; Granger causality; Purchasing Power Parity; PPP.

Reference to this paper should be made as follows: Brailsford, T.J., Penm, J. and Terrell, R.D. (2008) 'Causal relationship testing with applications to exchange rates', Int. J. Electronic Finance, Vol. 2, No. 1, pp.50-69.

Biographical notes: Professor Tim J. Brailsford is the Professor of Finance and Foundation Head of the UQ Business School at the University of Queensland, Australia. Professor Brailsford's work has appeared in many of the mainstream journals including the Journal of Banking \& Finance, Journal of Business and Journal of Empirical Finance.

Dr. Jack Penm is currently an Academic Staff Level C at the ANU. His main research interests are in: Zero-Non-Zero Patterned Vector Time-Series Modelling in investments and financial time series. He is an author/co-author of more than 50 papers published in various internationally recognised journals. 
Professor R. Deane Terrell is a Professor at the National Graduate School of Management at the ANU. His academic field of interest is time-series methods and forecasting and their application to economic and financial data. $\mathrm{He}$ has maintained an active research programme during his vice-chancellorship. $\mathrm{He}$ was awarded the Order of Australia in 2002.

\section{Introduction}

\subsection{Managerial implications for electronic finance}

Electronic finance using the internet represents a new and more efficient way of doing business. It has already brought significant organisational changes to corporations and governments as they strive to lower costs. Since the beginning of 1999, as countries have deregulated their telecommunications markets and have expanded access to the internet, electronic finance activities have expanded and changed at breathtaking speed. In the new economy it has mainly been the Information and Communication Technology (ICT) that has permitted rapid growth in the use of electronic finance, thus contributing to the evolution of capital markets. The lower cost in the ICT has especially promoted an increase in the rapidity of investments, in particular in exchange rate markets where knowledge-based skills are crucial. The focus of the information economy is to better understand and build upon the synergies surrounding developments in electronic finance.

Powerful computing equipment has had a dramatic impact on electronic finance, and has motivated development of innovative approaches to financial time series modelling and data processing (Refenes et al., 1996). The use of Vector Autoregressive Models (VAR) and Vector Error-Correction Models (VECM) for analysing dynamic relationships among financial variables, has become common in the literature (e.g., Lee, 1996; O'Neill et al., 2004; Wong et al., 2007). Moreover, relationships are often examined within the framework of a cointegrated system. The popularity of these models has been associated with the realisation that financial systems and relationships among financial variables are complex, which traditional time-series models have failed to fully capture.

Engle and Granger (1987) note that, for cointegrated systems, the VAR in first differences will be misspecified and the VAR in levels will ignore important constraints on the coefficient matrices. Although these constraints may be satisfied asymptotically, efficiency gains and improvements in forecasts are likely to result from their imposition. Hence Engle and Granger suggest that if a time-series system under study includes integrated variables of order 1 and cointegrating relations, then this system will be more appropriately specified as a VECM rather than a VAR. Comparisons of forecasting performance of VECMs versus VARs for cointegrated systems are reported in Engle and Yoo (1987) and LeSage (1990). ${ }^{1}$ The results of these studies indicate that the VECM is a more appropriate specification in terms of smaller long-term forecast errors, when the variables satisfy cointegration conditions. 
Subsequently, Johansen (1988) has proposed various algorithms for the estimation of cointegrating vectors in full-order VECM models, which contain all non-zero entries in the coefficient matrices. There are many examples of the use of full-order VECM models in the analysis of short-term dynamics and long-term cointegrating relationships (e.g., Johansen, 1995).

A problem can arise in relation to the use of full-order VECM models, as such models assume non-zero elements in all their coefficient matrices. As the number of elements to be estimated in these possibly over-parameterised models grows with the square of the number of variables, the degrees of freedom is heavily reduced.

A related problem is to provide satisfactory financial and economic interpretations for the estimated cointegrating vectors. As we earlier emphasised (Penm et al., 1997), it is important to introduce a priori information, usually to produce Zero-Non-Zero (ZNZ) patterns. To address this issue, we present a search algorithm and procedure to identify the optimal specification of a ZNZ patterned VECM for an I(1) system. ${ }^{2}$

Applications of VECM models to economic and financial time-series data have revealed that zero coefficient entries are indeed possible (King et al., 1991; Brailsford et al., 2006; Penm, 2007). ${ }^{3}$ An optimal VECM specification with zero entries suggests that the cointegrating vectors and the loading vectors may also contain zero entries. In this approach the zero entries are determined from data, with model selection criteria used to identify the optimal model (Penm et al., 1997). However the existence of zero entries has not been fully discussed in causality and cointegration theory. Specifically, the ability to detect the presence or absence of indirect causality and/or Granger non-causality is related to the identification of the optimal model. Further, the exact nature of the long-term cointegration relations will be crucially dependent upon finding those zero coefficient entries where the true structure does indeed include such zero entries.

This paper demonstrates a standard of testing causality in the context of a single ZNZ patterned VECM framework which allows for zero entries, that is, for time series of integrated order $\mathrm{I}(\mathrm{d}), \mathrm{d} \geq 1$. Moreover the Granger causal relations are detected from the coefficient matrices on the lagged difference terms, and from the error-correction terms. The paper also shows that identical causality detection for this $I(d)$ system can be revealed in the equivalent VAR framework. The developed algorithms will provide managers with a decision-making tool to evaluate some complex underlying relationships of which otherwise they could not be aware. Further demonstrations will be undertaken to apply the proposed algorithms to the relevant fields (Penm, 2008; Chen et al., 2006; Kumar and Turner, 2006).

The remainder of this paper is organised as follows. Section 2 reviews causality patterns in VAR modelling. Section 3 describes zero entries in a ZNZ patterned VAR and its equivalent VECM for an I(d) system. Causality detection in VECM modelling is also discussed. ${ }^{4}$ Two three-asset examples are then presented for illustrative purposes. To demonstrate the usefulness of the ZNZ patterned VECM for causality detection and cointegration investigation, Section 4 demonstrates two exchange rate applications. The first application examines the causal relationships between the movements of the Euro's exchange rate and the money supply. The second application conducts an examination of purchasing power parity focussing on the Yen. Concluding remarks are provided in Section 5. 


\section{Causality patterns in VAR Modelling}

First, as shown below, note that a VECM is identical to a VAR model with unit roots. Consider the following VAR model:

$$
\mathrm{y}(\mathrm{t})+\sum_{\tau=1}^{\mathrm{p}} \mathrm{A}_{\tau} \mathrm{y}(\mathrm{t}-\tau)=\mathrm{A}^{\mathrm{p}}(\mathrm{L}) \mathrm{y}(\mathrm{t})=\varepsilon(\mathrm{t})
$$

where $\varepsilon(\mathrm{t})$ is a (sx1) independently and identically distributed vector random process with $\mathrm{E}\{\varepsilon(\mathrm{t})\}=0$ and:

$$
\begin{aligned}
\mathrm{E}\left\{\varepsilon(\mathrm{t}) \varepsilon^{\prime}(\mathrm{t}-\tau)\right\}=\mathrm{V}, & \tau=0, \\
0, & \tau>0 .
\end{aligned}
$$

$\mathrm{A}_{\tau}, \tau=1,2, \ldots \mathrm{p}$ are (sxs) parameter matrices, and:

$$
\mathrm{A}^{\mathrm{p}}(\mathrm{L})=\mathrm{I}+\sum_{\tau=1}^{\mathrm{p}} \mathrm{A}_{\tau} \mathrm{L}^{\tau}
$$

L denotes the lag operator and the roots of $\left|\mathrm{A}^{\mathrm{p}}(\mathrm{L})\right|=0$ lie outside or on the unit circle. Further, we have the following relation:

$$
\mathrm{A}^{\mathrm{p}}(\mathrm{L})=\mathrm{A}^{\mathrm{p}}(1)+(\mathrm{I}-\mathrm{L})\left(\mathrm{I}+\sum_{\tau=1}^{\mathrm{p}-1} \mathrm{~A}_{\tau}^{*} \mathrm{~L}^{\tau}\right)
$$

It follows from the concept of cointegrated variables that $y(t)$ is said to be $I(1)$ if it contains at least one element which must be differenced before it becomes $\mathrm{I}(0)$ (Granger, $1981)$. Then $y(t)$ is said to be cointegrated of order 1 with the cointegrating vector, $\beta$, if $\beta^{\prime} y(t)$ becomes $I(0)$, where $y(t)$ has to contain at least two $I(1)$ variables. Under this assumption the identical VECM for (1) can be described as:

$$
\mathrm{A}^{*} \mathrm{y}(\mathrm{t}-1)+\mathrm{A}^{\mathrm{p}-1}(\mathrm{~L}) \Delta \mathrm{y}(\mathrm{t})=\varepsilon(\mathrm{t}),
$$

where $\mathrm{y}(\mathrm{t})$ contains both $\mathrm{I}(0)$ and $\mathrm{I}(1)$ variables, $\Delta=(\mathrm{I}-\mathrm{L}), \mathrm{A}^{*}=\mathrm{A}^{\mathrm{p}}(1), \mathrm{A}^{*} \mathrm{y}(\mathrm{t}-1)$ is stationary, and:

$$
\mathrm{A}^{\mathrm{p}-1}(\mathrm{~L})=\mathrm{I}+\sum_{\tau=1}^{\mathrm{p}-1} \mathrm{~A}_{\tau}^{*} \mathrm{~L}^{\tau}
$$

The first term in (2) (i.e., $\mathrm{A}^{*} \mathrm{y}(\mathrm{t}-1)$ ) is the error-correction term, which contains the long-term cointegrating relationships. $\mathrm{A}^{\mathrm{p}-1}(\mathrm{~L}) \Delta \mathrm{y}(\mathrm{t})$ is referred to as the VAR part of the VECM, describing the short-term dynamics. Because $y(t)$ is cointegrated of order 1 , the long-term impact matrix $A^{*}$ must be singular. As a result $A^{*}=\alpha \beta^{\prime}$ where $\alpha$ and $\beta$ are (sxr) matrices and the rank of $A^{*}$ is $r$, where $r<s$. The columns of $\beta$ are the cointegrating vectors, and the rows of $\alpha$ are the loading vectors.

Now, consider a bivariate system where $y(t)=\left[y_{1}(t) y_{2}(t)\right]^{\prime}$, then the following natural way of defining a causal ordering may be developed.

Consider $a_{i j}^{p}(L)=\sum_{\tau=1}^{p} \alpha_{i j}^{\tau} L^{\tau}$, where $a_{i j}^{p}(L)$ is the $(i, j)$-th entry of $A^{p}(L)$.

Definition $(a)$ : $y_{1}(t)$ Granger non-causes $y_{2}(t)$, and $y_{2}(t)$ Granger causes $y_{1}(t)$ if and only if $\mathrm{a}_{21}^{\mathrm{p}}(\mathrm{L})=0$ and at least one $\alpha_{12}^{\tau}, \tau=1, \ldots, \mathrm{p}$, is non-zero. 
That means:

$$
A^{p}(L)=\left[\begin{array}{cc}
a_{11}^{p}(L) & a_{12}^{p}(L) \\
0 & a_{22}^{p}(L)
\end{array}\right],
$$

and the coefficients, $\mathrm{a}_{12}^{\tau}, \tau=1, \ldots, \mathrm{p}$ in $\mathrm{a}_{12}^{\mathrm{p}}(\mathrm{L})$ can be either zero or non-zero, but at least one $\mathrm{a}_{12}^{\tau}$ is non-zero.

Further, there exist $2^{\mathrm{p}-1}$ different patterns of $\mathrm{a}_{21}^{\mathrm{p}}(\mathrm{L})$ in this bivariate system, indicating that $\mathrm{y}_{1}(\mathrm{t})$ Granger non-causes $\mathrm{y}_{2}(\mathrm{t})$, and $\mathrm{y}_{2}(\mathrm{t})$ Granger causes $\mathrm{y}_{1}(\mathrm{t})$.

Definition $(b)$ : $y_{2}(t)$ Granger non-causes $y_{1}(t)$, and $y_{1}(t)$ Granger causes $y_{2}(t)$ if and only if $\mathrm{a}_{12}^{\mathrm{p}}(\mathrm{L})=0$ and at least one $\alpha_{21}^{\tau}, \tau=1, \ldots, \mathrm{p}$, is non-zero.

That means:

$$
A^{p}(L)=\left[\begin{array}{cc}
a_{11}^{p}(L) & 0 \\
a_{21}^{p}(L) & a_{22}^{p}(L)
\end{array}\right],
$$

and the coefficients, $a_{21}^{\tau}, \tau=1, \ldots, p$ in $a_{21}^{p}(L)$ can be either zero or non-zero, but at least one $\alpha_{21}^{\tau}$ is non-zero.

Definition $(c)$ : $y_{2}(t)$ Granger causes $y_{1}(t)$, and $y_{1}(t)$ Granger causes $y_{2}(t)$ if and only if $\mathrm{a}_{12}^{\mathrm{p}}(\mathrm{L}) \neq 0$ and $\mathrm{a}_{21}^{\mathrm{p}}(\mathrm{L}) \neq 0$.

Definition $(d)$ : $y_{2}(t)$ Granger non-causes $y_{1}(t)$, and $y_{1}(t)$ Granger non-causes $y_{2}(t)$ if and only if $\mathrm{a}_{12}^{\mathrm{p}}(\mathrm{L})=0$ and $\mathrm{a}_{21}^{\mathrm{p}}(\mathrm{L})=0$.

The above causality patterns can be detected from the optimal selected ZNZ patterned VAR proposed in Penm and Terrell (1984). More general causal patterns can be treated using definitions suggested by Hsiao (1982).

Consider the following trivariate system:

$$
\left[\begin{array}{ccc}
a_{11}^{\mathrm{p}}(L) & a_{12}^{\mathrm{p}}(\mathrm{L}) & \mathrm{a}_{13}^{\mathrm{p}}(\mathrm{L}) \\
\mathrm{a}_{21}^{\mathrm{p}}(\mathrm{L}) & \mathrm{a}_{22}^{\mathrm{p}}(\mathrm{L}) & \mathrm{a}_{23}^{\mathrm{p}}(\mathrm{L}) \\
0 & \mathrm{a}_{32}^{\mathrm{p}}(\mathrm{L}) & \mathrm{a}_{33}^{\mathrm{p}}(\mathrm{L})
\end{array}\right]\left[\begin{array}{c}
\mathrm{y}_{1}(\mathrm{t}) \\
\mathrm{y}_{2}(\mathrm{t}) \\
\mathrm{y}_{3}(\mathrm{t})
\end{array}\right]=\varepsilon(\mathrm{t}),
$$

which describes $\mathrm{y}_{1}(\mathrm{t})$ causing $\mathrm{y}_{3}(\mathrm{t})$ but only through $\mathrm{y}_{2}(\mathrm{t})$. In this trivariate system the above indirect causality implies $\mathrm{a}_{31}^{\mathrm{p}}(\mathrm{L})=0, \mathrm{a}_{21}^{\mathrm{p}}(\mathrm{L}) \neq 0$ and $\mathrm{a}_{32}^{\mathrm{p}}(\mathrm{L}) \neq 0$. Also, $\left\{\alpha_{12}^{\tau}=0\right.$ or $\left.\neq 0\right\},\left\{\alpha_{13}^{\tau}=0\right.$ or $\left.\neq 0\right\}$ and $\left\{\alpha_{23}^{\tau}=0\right.$ or $\left.\neq 0\right\}, \tau=1, \ldots, p$.

The greater the number of components, $y_{i}(t), i=1,2, \ldots$, the more complicated are the causal patterns that may be detected. ${ }^{5}$

\section{Zero entries in a ZNZ patterned VAR and its equivalent VECM for an I(d) system}

This section of the paper consists of two parts. The first part shows the equivalence between ZNZ-patterned VECMs and the corresponding VAR models. The second part presents two three-asset examples to demonstrate the equivalence. Thus, this section contributes both theoretical development and numerical examples to show the equivalence of causality detection in VAR and VECM modelling. 


\subsection{Equivalence between VECM and VAR models}

In an I(d) system the equivalent VECM derived from (1) can be described as follows:

$$
\mathrm{A}^{\mathrm{p}}(1) \mathrm{y}(\mathrm{t}-1)+\mathrm{A}^{\mathrm{p}-1}(1) \Delta \mathrm{y}(\mathrm{t}-1)+\ldots+\mathrm{A}^{\mathrm{p}-\mathrm{d}+1}(1) \Delta^{\mathrm{d}-1} \mathrm{y}(\mathrm{t}-1)+\mathrm{A}^{\mathrm{p}-\mathrm{d}}(\mathrm{L}) \Delta^{\mathrm{d}} \mathrm{y}(\mathrm{t})=\epsilon(\mathrm{t}),
$$

where $\mathrm{A}^{\mathrm{p}-\mathrm{i}}(1) \Delta^{\mathrm{i}} \mathrm{y}(\mathrm{t}-1)$ are stationary, $\mathrm{i}=0, \ldots, \mathrm{d}-1$. The first $\mathrm{d}$ terms are the error-correction terms, while $\mathrm{A}^{\mathrm{p}-\mathrm{d}}(\mathrm{L}) \Delta^{\mathrm{d}} \mathrm{y}(\mathrm{t})$ is said to be the autoregressive part of the model.

In order to show the equivalence between ZNZ-patterned VECMs and the corresponding VAR models, the following two properties need to be established:

(i) If $y_{j}$ does not Granger-cause $y_{i}$ then every $(i, j)$-th entry must be zero for all coefficient matrices in the VAR. Also all (i,j)-th coefficient elements in the equivalent VECM are zeros.

(ii) If $y_{j}$ does Granger-cause $y_{i}$, then the (i,j)-th element of $A^{p}(L)$ in the VAR is non-zero. In addition at least a single (i,j)-th coefficient element is non-zero in $\mathrm{A}^{\mathrm{p}}(1), \mathrm{A}^{\mathrm{p}-1}(1), \ldots, \mathrm{A}^{\mathrm{p}-\mathrm{d}+1}(1)$, or $\mathrm{A}^{\mathrm{p}-\mathrm{d}}(\mathrm{L})$ in the equivalent VECM.

To prove Property (i), we have the following relations in the VAR and its equivalent VECM:

$$
A^{k}(L)=A^{k}(1) L+A^{k-1}(L)(I-L), k=p, p-1, \ldots, p-d+1 .
$$

Since Granger causality detection is crucially dependent on the positions of off-diagonal zero entries in the coefficient matrices, we therefore focus on the positions where $\mathrm{i} \neq \mathrm{j}$.

If the $(i, j)$-th entries of $A^{k}(L), A^{k}(1)$, and $A^{k-1}(L)$ are $a_{i j}(L), a_{i j}(1)$, and $e_{i j}(L)$ respectively, we have:

$$
a_{i j}(L)=a_{i j}(1) L+e_{i j}(L)(1-L), i \neq j .
$$

Now we define $e_{i j}(L)$ by:

$$
\mathrm{e}_{\mathrm{ij}}(\mathrm{L})=\mathrm{e}_{1} \mathrm{~L}+\ldots+\mathrm{e}_{\mathrm{k}-1} \mathrm{~L}^{\mathrm{k}-1},
$$

and thus:

$$
e_{i j}(L)(1-L)=e_{1} L+\left(e_{2}-e_{1}\right) L^{2}+\ldots+\left(e_{k-1}-e_{k-2}\right) L^{k-1}-e_{k-1} L^{k} .
$$

If $\mathrm{a}_{\mathrm{ij}}(\mathrm{L})=0$, then $\mathrm{a}_{\mathrm{ij}}(1)$ will also be zero. From (5) we have $\mathrm{e}_{\mathrm{ij}}(\mathrm{L})(1-\mathrm{L})=0$, and $(6)$ produces $\mathrm{e}_{1}=0, \mathrm{e}_{2}-\mathrm{e}_{1}=0, \ldots, \mathrm{e}_{\mathrm{k}-1}-\mathrm{e}_{\mathrm{k}-2}=0, \mathrm{e}_{\mathrm{k}-1}=0$, which lead to $\mathrm{e}_{\mathrm{i}}=0, \mathrm{i}=1, \ldots$, $\mathrm{k}-1$, and therefore $\mathrm{c}_{\mathrm{ij}}(\mathrm{L})=0$.

At this point, if the $(i, j)$-th entry of $A^{k}(L)$ is zero, then the (i,j)-th elements of both $A^{k}(1)$ and $A^{k-1}(L)$ are zeros. Therefore we can conclude that if every $(i, j)$-th entry is zero for all coefficient matrices in a VAR then all $(\mathrm{i}, \mathrm{j})$-th coefficient elements in the error-correction terms and in the vector autoregressive part of the VECM, will also be zeros.

Analogously it is evident that if the (i,j)-th elements of all $A^{k}(1), k=p, p-1, \ldots$, $p-d+1$ and $A^{k-1}(L)$ in $(3)$ are zeros then the $(i, j)$-th entry of $A^{p}(L)$ in the equivalent VAR will be zero. Therefore we can conclude that if all $(i, j)$-th coefficient elements in the error-correction terms and all $(\mathrm{i}, \mathrm{j})$-th coefficient elements in the vector autoregressive part of the VECM are zeros, then every $(\mathrm{i}, \mathrm{j})$-th entry is zero for all coefficient matrices in a VAR. Thus we establish Property (i). 
To prove Property (ii), we can express (4) as follows:

$$
\begin{aligned}
& A^{p}(L)=A^{p}(1) L+A^{p-1}(L)-A^{p-1}(L) L \\
& A^{p-1}(L)=A^{p-1}(1) L+A^{p-2}(L)-A^{p-2}(L) L \\
& \vdots \\
& A^{p-d+1}(L)=A^{p-d+1}(1) L+A^{p-d}(L)-A^{p-d}(L) L
\end{aligned}
$$

From (7.3), it is obvious that if the (i,j)-th element of $A^{p-d+1}(1)$ is non-zero, then the $(i, j)$-th element of $A^{p-d+1}(L)$ is non-zero. Also if the (i,j)-th element of $A^{p-d}(L)$ is non-zero, then a zero $(i, j)$-th element of $A^{p-d+1}(1)$ leads to a non-zero $(i, j)$ element of $A^{p-d+1}(L)$. Thus, we have proved that if there exists a non-zero $(i, j)$-th element in either $A^{k}(1)$ or $\mathrm{A}^{\mathrm{k}-1}(\mathrm{~L}), \mathrm{k}=\mathrm{p}, \mathrm{p}-1, \ldots, \mathrm{p}-\mathrm{d}+1$ in $(4)$, then the corresponding (i,j)-th element of $\mathrm{A}^{\mathrm{k}}(\mathrm{L})$ is non-zero. This outcome shows that if any single (i,j)-th element is non-zero in any one of the $d$ matrices, $\mathrm{A}^{\mathrm{k}}(1), \mathrm{k}=\mathrm{p}, \mathrm{p}-1, \ldots, \mathrm{p}-\mathrm{d}+1$, or $\mathrm{A}^{\mathrm{p}-\mathrm{d}}(\mathrm{L})$ in the VECM in (3) is non-zero, then the $(i, j)$-th element of $A^{p}(L)$ in the equivalent VAR is non-zero.

Analogously from (7.1) if the $(i, j)$-th element of $\mathrm{A}^{\mathrm{p}}(\mathrm{L})$ is non-zero, then at least the $(i, j)$-th element is non-zero in one of the following d coefficient matrices, or $A^{p-d}(L)$ :

$$
\mathrm{A}^{\mathrm{p}}(1), \mathrm{A}^{\mathrm{p}-1}(1), \ldots, \mathrm{A}^{\mathrm{p}-\mathrm{d}+1}(1) .
$$

Therefore, we have demonstrated that Property (ii) is established.

An indirect causality from $y_{j}$ to $y_{i}$ through $y_{m}$ indicates $y_{j}$ causing $y_{i}$ but only through $y_{m}$. Hence, $y_{j}$ Granger-causes $y_{m}, y_{m}$ Granger-causes $y_{i}$, and $y_{j}$ does not Granger-cause $\mathrm{y}_{\mathrm{i}}$ directly. It can be easily demonstrated that the VAR in (1) has non-zero $(\mathrm{m}, \mathrm{j})$-th and $(\mathrm{i}, \mathrm{m})$-th elements and a zero (i,j)-th element of $\mathrm{A}^{\mathrm{p}}(\mathrm{L})$. The identical indirect causality can also be shown in the equivalent VECM. Thus any questions on the nature of the causal pattern can be addressed either through the VAR approach or the VECM approach, and the causal pattern identified is identical.

It is noteworthy that Johansen (1988) has proposed the following VECM equivalent to the VAR model of (1) in an I(1) system:

$$
\Gamma^{\mathrm{p}-1}(\mathrm{~L}) \Delta \mathrm{y}(\mathrm{t})+\mathrm{A}^{*} \mathrm{y}(\mathrm{t}-\mathrm{p})=\varepsilon(\mathrm{t})
$$

where:

$$
\Gamma^{\mathrm{p}-1}(\mathrm{~L})=\mathrm{I}+\sum_{\mathrm{i}=1}^{\mathrm{p}-1} \Gamma_{\mathrm{i}} \mathrm{L}^{\mathrm{i}} .
$$

The error-correction term of this VECM is $A^{*} y(t-p)$, while the error-correction term in (2) is $A^{*} y(t-1)$. Thus we have:

$$
\Gamma_{\mathrm{k}}=\mathrm{I}_{\mathrm{p}}+\mathrm{A}_{1}+\cdots+\mathrm{A}_{\mathrm{k}}, \mathrm{k}=1, \ldots, \mathrm{p}-1,
$$

and:

$$
\mathrm{A}^{*}=\mathrm{I}_{\mathrm{p}}+\mathrm{A}_{1}+\cdots+\mathrm{A}_{\mathrm{p}} .
$$


Recall that $a_{i j}^{k}$ denotes the (i,j)-th entry of $A_{k}$. Let $g_{i j}^{k}$ and $a_{i j}^{*}$ denote the $(i, j)$-th entry of $\Gamma_{\mathrm{k}}$ and $\mathrm{A}^{*}$ respectively. From (9) it is obvious that all $\mathrm{p}$ entries, $\left\{\mathrm{a}_{\mathrm{ij}}^{\mathrm{k}}, \mathrm{k}=1, \ldots, \mathrm{p}\right\}$ are zeros; then $\mathrm{a}_{\mathrm{ij}}^{*}$ is zero and all $\left\{\mathrm{g}_{\mathrm{ij}}^{\mathrm{k}}, \mathrm{k}=1, \ldots, \mathrm{p}-1\right\}$ are also zeros. Similarly if $\mathrm{a}_{\mathrm{ij}}^{*}$ and all $\left\{\mathrm{g}_{\mathrm{ij}}^{\mathrm{k}}, \mathrm{k}=1, \ldots, \mathrm{p}-1\right\}$ are zeros, then $\left\{\mathrm{a}_{\mathrm{ij}}^{\mathrm{k}}, \mathrm{k}=1, \ldots, \mathrm{p}\right\}$ are zeros.

Therefore we can conclude that Property (i) is valid for (8) and the equivalent VAR.

We then show that if any single $a_{i j}^{k}, k=1, \ldots, p$ in the VAR is non-zero, then the $(\mathrm{i}, \mathrm{j})$-entry is non-zero in either $\mathrm{A}^{*}$ or $\Gamma^{\mathrm{p}-1}(\mathrm{~L})$.

To begin with, we rewrite (9) as:

$$
\begin{aligned}
& \Gamma_{1}=\mathrm{I}_{\mathrm{p}}+\mathrm{A}_{1}, \\
& \Gamma_{2}=\Gamma_{1}+\mathrm{A}_{2}, \\
& \ldots \\
& \Gamma_{\mathrm{k}}=\Gamma_{\mathrm{k}-1}+\mathrm{A}_{\mathrm{k}}, \mathrm{k}=2, \ldots, \mathrm{p}-1 .
\end{aligned}
$$

From (11) if $\mathrm{a}_{\mathrm{ij}}^{1}$ is non-zero, then $\mathrm{g}_{\mathrm{ij}}^{1}$ is non-zero. However if $\mathrm{a}_{\mathrm{ij}}^{1}$ is zero, then $\mathrm{g}_{\mathrm{ij}}^{1}$ will be zero. We then inspect $\mathrm{a}_{\mathrm{ij}}^{2}$. Similarly, if $\mathrm{a}_{\mathrm{ij}}^{2}$ is non-zero, then $\mathrm{g}_{\mathrm{ij}}^{2}$ is non-zero. In addition, it is obvious that if $a_{i j}^{p}$ is non-zero and all $a_{i j}^{k}, k=1, \ldots, p-1$ are zeros, then $a_{i j}^{*}$ is non-zero, even though all $\mathrm{g}_{\mathrm{ij}}^{\mathrm{k}}, \mathrm{k}=1, \ldots, \mathrm{p}-1$ are zeroes.

Analogously it can be proved that if any single (i,j)-entry is non-zero in either $A^{*}$ or $\Gamma^{\mathrm{p}-1}(\mathrm{~L})$, then the $(\mathrm{i}, \mathrm{j})$-th entry of $\mathrm{A}^{\mathrm{p}}(\mathrm{L})$ in the equivalent VAR is non-zero.

Therefore, the above demonstrates that if $y_{j}$ does Granger-cause $y_{i}$ in (8), then the $(i, j)$-th element of $A^{p}(L)$ in the VAR is non-zero. In addition the (i,j)-entry is also non-zero in either $A^{*}$ or $\Gamma^{p-1}(L)$ or both in the equivalent VECM. Thus the causal pattern identified through the VAR approach or the VECM approach is identical.

\subsection{Illustrations}

To show the equivalence of causality detection in VAR and VECM modelling, two three-asset examples are presented to illustrate this outcome. The first example involves two cointegrating relations and one unit root, while the second one involves one cointegrating relation and two unit roots.

In considering a VAR model with ZNZ patterned coefficient matrices, we allow for zero entries in the parameter matrices $A_{\tau}$ of (1). If $y_{1, t}, y_{2, t}$ and $y_{3, t}$ are the log prices of three assets, then the returns on the assets are defined by $\Delta \mathrm{y}_{1, t}=z_{1, t}, \Delta y_{2, t}=z_{2, t}$ and $\Delta \mathrm{y}_{3, \mathrm{t}}=\mathrm{z}_{3, \mathrm{t}}$. All $\mathrm{z}_{1, \mathrm{t}}, \mathrm{z}_{2, \mathrm{t}}$ and $\mathrm{z}_{3, \mathrm{t}}$ are jointly determined by the following equations:

$$
\begin{aligned}
& \mathrm{z}_{1, \mathrm{t}}-0.6 \mathrm{z}_{1, \mathrm{t}-1}-0.8 \mathrm{z}_{2, \mathrm{t}-1}=\varepsilon_{1, \mathrm{t}} \\
& \mathrm{z}_{2, \mathrm{t}}-0.1 \mathrm{z}_{1, \mathrm{t}-1}-0.4 \mathrm{z}_{2, \mathrm{t}-1}-0.8 \mathrm{z}_{3, \mathrm{t}-1}=\varepsilon_{2, \mathrm{t}} \\
& \mathrm{z}_{3, \mathrm{t}}-0.1 \mathrm{z}_{2, \mathrm{t}-1}-0.8 \mathrm{z}_{3, \mathrm{t}-1}=\varepsilon_{3, \mathrm{t}} .
\end{aligned}
$$


The equivalent VAR model of this system can then be presented as:

$$
\left[\begin{array}{c}
\mathrm{z}_{1, \mathrm{t}} \\
\mathrm{z}_{2, \mathrm{t}} \\
\mathrm{z}_{3, \mathrm{t}}
\end{array}\right]+\left[\begin{array}{ccc}
-0.6 & -0.8 & 0 \\
-0.1 & -0.4 & -0.8 \\
0 & -0.1 & -0.8
\end{array}\right]\left[\begin{array}{l}
\mathrm{z}_{1, \mathrm{t}-1} \\
\mathrm{z}_{2, \mathrm{t}-1} \\
\mathrm{z}_{3, \mathrm{t}-1}
\end{array}\right]=\left[\begin{array}{c}
\varepsilon_{1, \mathrm{t}} \\
\varepsilon_{2, \mathrm{t}} \\
\varepsilon_{3, \mathrm{t}}
\end{array}\right] .
$$

In this VAR model, both $\mathrm{a}_{13}^{1}(\mathrm{~L})$ and $\mathrm{a}_{31}^{1}(\mathrm{~L})$ are zeros. Thus Granger non-causality exists between the first asset's return and the third asset's return. Further, $a_{21}^{1}(L) \neq 0$ and $a_{32}^{1}(L) \neq 0$, which indicate indirect causality from the first to the third asset's return via the second asset's return.

To inspect unit roots, we have the following relationship to determine the roots of the characteristic polynomial:

$$
\operatorname{det}\left[\begin{array}{ccc}
1-0.6 \mathrm{~L} & -0.8 \mathrm{~L} & 0 \\
-0.1 \mathrm{~L} & 1-0.4 \mathrm{~L} & -0.8 \mathrm{~L} \\
0 & -0.1 \mathrm{~L} & 1-0.8 \mathrm{~L}
\end{array}\right]=0
$$

This relationship leads to $\operatorname{det}\left\{\left(1-0.8 \mathrm{~L}+0.08 \mathrm{~L}^{2}\right)(1-\mathrm{L})\right\}=0$. Therefore a single unit root is detected.

Next, we turn to the VECM modelling. By adding and subtracting a $\left[z_{1, t-1} \quad z_{2, t-1}\right.$ $\left.\mathrm{z}_{3, \mathrm{t}-1}\right]^{\prime}$ vector to the left side of Equation (12), the VAR in (12) can be presented as follows:

$$
\left[\begin{array}{l}
\mathrm{z}_{1, \mathrm{t}} \\
\mathrm{z}_{2, \mathrm{t}} \\
\mathrm{z}_{3, \mathrm{t}}
\end{array}\right]-\left[\begin{array}{c}
\mathrm{z}_{1, \mathrm{t}-1} \\
\mathrm{z}_{2, \mathrm{t}-1} \\
\mathrm{z}_{3, \mathrm{t}-1}
\end{array}\right]+\left[\begin{array}{ccc}
0.4 & -0.8 & 0 \\
-0.1 & 0.6 & -0.8 \\
0 & -0.1 & 0.2
\end{array}\right]\left[\begin{array}{l}
\mathrm{z}_{1, \mathrm{t}-1} \\
\mathrm{z}_{2, \mathrm{t}-1} \\
\mathrm{z}_{3, \mathrm{t}-1}
\end{array}\right]=\left[\begin{array}{c}
\varepsilon_{1, \mathrm{t}} \\
\varepsilon_{2, \mathrm{t}} \\
\varepsilon_{3, \mathrm{t}}
\end{array}\right] .
$$

Thus we have:

$$
\left[\begin{array}{c}
\Delta \mathrm{z}_{1, \mathrm{t}} \\
\Delta \mathrm{z}_{2, \mathrm{t}} \\
\Delta \mathrm{z}_{3, \mathrm{t}}
\end{array}\right]+\left[\begin{array}{ccc}
0.4 & -0.8 & 0 \\
-0.1 & 0.6 & -0.8 \\
0 & -0.1 & 0.2
\end{array}\right]\left[\begin{array}{c}
\mathrm{z}_{1, \mathrm{t}-1} \\
\mathrm{z}_{2, \mathrm{t}-1} \\
\mathrm{z}_{3, \mathrm{t}-1}
\end{array}\right]=\left[\begin{array}{c}
\varepsilon_{1, \mathrm{t}} \\
\varepsilon_{2, \mathrm{t}} \\
\varepsilon_{3, \mathrm{t}}
\end{array}\right]
$$

Since the (1,3)-th and (3,1)-th elements of the VECM are zeros, we can conclude that Granger non-causality exists between $\mathrm{z}_{1, \mathrm{t}}$ and $\mathrm{z}_{3, \mathrm{t}}$. Indirect causality is also detected from $z_{1, t}$ to $z_{3, t}$ through $z_{2, t}$, due to all remaining non-zero elements. Hence causal relations indicated by the VECM are identical to these relations shown in the equivalent VAR in (12).

In addition, the rank of the impact matrix in (13) is 2 , not 3 . This matrix can be decomposed as follows:

$$
\left[\begin{array}{ccc}
0.4 & -0.8 & 0 \\
-0.1 & 0.6 & -0.8 \\
0 & -0.1 & 0.2
\end{array}\right]=\left[\begin{array}{cc}
-0.4 & 0 \\
0.1 & -0.4 \\
0 & 0.1
\end{array}\right]\left[\begin{array}{ccc}
-1 & 2 & 0 \\
0 & -1 & 2
\end{array}\right] .
$$


The following two ZNZ patterned cointegrating vectors are also identified:

$$
\left[\begin{array}{lll}
-1 & 2 & 0
\end{array}\right] \text { and }\left[\begin{array}{lll}
0 & -1 & 2
\end{array}\right] \text {. }
$$

Further, the first selected cointegrating vector demonstrates that the first asset's return and the second asset's return are cointegrated. The different sign occurring in $\mathrm{z}_{1, \mathrm{t}-1}$ and $\mathrm{z}_{2, \mathrm{t}-1}$ indicates that, ceteris paribus, when the first asset's return rises, the second asset's return increases. It also implies that, ceteris paribus, a decrease in the first asset's return leads to a fall of the second asset's return. The second selected cointegrating vector indicates that the cointegrating relationship exists between the second asset's return and the third asset's return. The different sign occurring in $\mathrm{z}_{2, \mathrm{t}-1}$ and $\mathrm{z}_{3, \mathrm{t}-1}$ also reveals that, ceteris paribus, a rise in the second asset's return leads to an increase in the third asset's return.

For the second example, all $\mathrm{z}_{1, \mathrm{t}}, \mathrm{z}_{2, \mathrm{t}}$ and $\mathrm{z}_{3, \mathrm{t}}$ are determined by the following equations:

$$
\begin{aligned}
& \mathrm{z}_{1, \mathrm{t}}-\mathrm{z}_{1, \mathrm{t}-1}=\varepsilon_{1, \mathrm{t}} \\
& \mathrm{z}_{2, \mathrm{t}}+\mathrm{z}_{1, \mathrm{t}-1}-0.5 \mathrm{z}_{2, \mathrm{t}-1}-0.8 \mathrm{z}_{3, \mathrm{t}-1}=\varepsilon_{2, \mathrm{t}} \\
& \mathrm{z}_{3, \mathrm{t}}-\mathrm{z}_{3, \mathrm{t}-1}=\varepsilon_{3, \mathrm{t}} .
\end{aligned}
$$

The VAR model of this system can then be shown as:

$$
\left[\begin{array}{l}
\mathrm{z}_{1, \mathrm{t}} \\
\mathrm{z}_{2, \mathrm{t}} \\
\mathrm{z}_{3, \mathrm{t}}
\end{array}\right]+\left[\begin{array}{ccc}
-1.0 & 0 & 0 \\
1 & -0.5 & -0.8 \\
0 & 0 & -1
\end{array}\right]\left[\begin{array}{l}
\mathrm{z}_{1, \mathrm{t}-1} \\
\mathrm{z}_{2, \mathrm{t}-1} \\
\mathrm{z}_{3, \mathrm{t}-1}
\end{array}\right]=\left[\begin{array}{c}
\varepsilon_{1, \mathrm{t}} \\
\varepsilon_{2, \mathrm{t}} \\
\varepsilon_{3, \mathrm{t}}
\end{array}\right] .
$$

In this VAR model $a_{21}^{1}(L)$ and $a_{23}^{1}(L)$ are non-zeros, while the remaining $a_{i j}^{1}(L), i \neq j$, are zeros. Thus Granger causality exists only from both the first asset's return and the third asset's return to the second asset's return.

To determine the roots of the characteristic polynomial for inspecting unit roots, we have:

$$
\operatorname{det}\left[\begin{array}{ccc}
1-\mathrm{L} & 0 & 0 \\
\mathrm{~L} & 1-0.5 \mathrm{~L} & -0.8 \mathrm{~L} \\
0 & 0 & 1-\mathrm{L}
\end{array}\right]=0
$$

which leads to $\operatorname{det}\left\{(1-0.5 \mathrm{~L})(1-\mathrm{L})^{2}\right\}=0$. Therefore two unit roots are detected.

Next, the VAR in (14) can be presented as follows:

$$
\left[\begin{array}{l}
\mathrm{z}_{1, \mathrm{t}} \\
\mathrm{z}_{2, \mathrm{t}} \\
\mathrm{z}_{3, \mathrm{t}}
\end{array}\right]-\left[\begin{array}{c}
\mathrm{z}_{1, \mathrm{t}-1} \\
\mathrm{z}_{2, \mathrm{t}-1} \\
\mathrm{z}_{3, \mathrm{t}-1}
\end{array}\right]+\left[\begin{array}{ccc}
0 & 0 & 0 \\
1 & 0.5 & -0.8 \\
0 & 0 & 0
\end{array}\right]\left[\begin{array}{l}
\mathrm{z}_{1, \mathrm{t}-1} \\
\mathrm{z}_{2, \mathrm{t}-1} \\
\mathrm{z}_{3, \mathrm{t}-1}
\end{array}\right]=\left[\begin{array}{c}
\varepsilon_{1, \mathrm{t}} \\
\varepsilon_{2, \mathrm{t}} \\
\varepsilon_{3, \mathrm{t}}
\end{array}\right] .
$$

Thus we have the following equivalent VECM:

$$
\left[\begin{array}{c}
\Delta \mathrm{z}_{1, \mathrm{t}} \\
\Delta \mathrm{z}_{2, \mathrm{t}} \\
\Delta \mathrm{z}_{3, \mathrm{t}}
\end{array}\right]+\left[\begin{array}{ccc}
0 & 0 & 0 \\
1 & 0.5 & -0.8 \\
0 & 0 & 0
\end{array}\right]\left[\begin{array}{c}
\mathrm{z}_{1, \mathrm{t}-1} \\
\mathrm{z}_{2, \mathrm{t}-1} \\
\mathrm{z}_{3, \mathrm{t}-1}
\end{array}\right]=\left[\begin{array}{c}
\varepsilon_{1, \mathrm{t}} \\
\varepsilon_{2, \mathrm{t}} \\
\varepsilon_{3, \mathrm{t}}
\end{array}\right] .
$$


Since only (2,1)-th and (2,3)-th elements of the off-diagonal elements in the VECM are non-zeros, we can conclude that Granger causality exists only from both $\mathrm{z}_{1, \mathrm{t}}$ and $\mathrm{z}_{3, \mathrm{t}}$ to $\mathrm{z}_{2, \mathrm{t}}$, due to all remaining zero elements. Hence causal relations indicated by the VECM are identical to these relations shown in the equivalent VAR in (14).

Since the rank of the impact matrix in (15) is 1 , not 3 , we can have the following decomposition:

$$
\left[\begin{array}{ccc}
0 & 0 & 0 \\
1 & 0.5 & -0.8 \\
0 & 0 & 0
\end{array}\right]=\left[\begin{array}{l}
0 \\
1 \\
0
\end{array}\right]\left[\begin{array}{lll}
1 & 0.5 & -0.8
\end{array}\right] .
$$

Thus the following single $\mathrm{ZNZ}$ patterned cointegrating vector is identified:

$$
\left[\begin{array}{lll}
1 & 0.5 & -0.8
\end{array}\right] \text {. }
$$

Further, the selected cointegrating vector demonstrates that the first asset's return, the second asset's return and the third asset's return are cointegrated. The same sign occurring in $\mathrm{z}_{1, \mathrm{t}-1}$ and $\mathrm{z}_{2, \mathrm{t}-1}$, and the different sign occurring in $\mathrm{z}_{1, \mathrm{t}-1}$ and $\mathrm{z}_{3, \mathrm{t}-1}$ indicate that, ceteris paribus, an increase in the first asset's return leads to a fall of the second asset's return, but a rise of the third asset's return.

\section{Exchange rate applications}

The above sections have shown ZNZ patterned VECM modelling. As argued earlier, the use of this procedure is particularly suited to financial variables in which complex relationships exist. In the next two subsections, two empirical applications of the modelling procedure using foreign exchange examples are presented.

\subsection{Relationship between movements of the Euro and the money supply}

The first application focuses on the detection of causal relationships between movements in the Euro's exchange rate (relative to the US dollar) and the money supply in the European Monetary Union.

The Euro was introduced on 1 January 1999 as official currency. To date the Euro has become the second most widely traded currency at the international level, behind the US dollar and ahead of the Japanese Yen. During the first year of trading, the value of the Euro relative to the US dollar fell markedly. The Euro's weakness throughout this period confounded earlier general expectations that it would trend upwards relative to the US dollar (see ECB, 2001).

Money supply in the Euro area is measured by the standard stock of money (M3). It consists of sight deposits, shorter deposits of up to two years, and marketable instruments. Figure 1 shows that for the entire year of 1999 the monthly measures of M3 were always higher than the reference value of $4.5 \%$ set by the Governing Council of the European Central Bank. The Governing Council has adopted a price stability-oriented monetary policy strategy, that is, the rate of monetary expansion is designed to achieve the objective of price stability. Thus it may be presumed that the $4.5 \%$ benchmark for the growth rate of M3 is regarded as the level to accomplish this objective. 
Figure 1 M3 growth and the reference value in the European Monetary Union

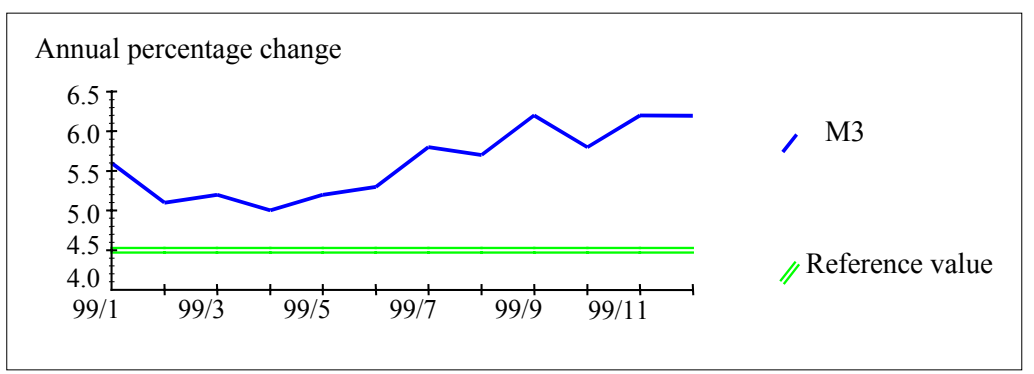

Source: $\mathrm{ECB}$

Our task is to assess the nature of the influence of the money supply on the exchange rate, ceteris paribus. In the gold standard era, since the gold reserves of a country were limited (if they were not gold producers), the growth rate of money supply was related to the level of country's reserves. The unmanaged growth of money supply could lead to changes in value of a country's currency. In the present circumstances of a floating exchange rate system, currencies are expected to fluctuate according to supply and demand. In order to smooth the market, governments may adjust the money supply which directly or indirectly influences the foreign exchange rate. However governments are not able to control the exchange rate over a long period without regard to economic fundamentals.

The most widely held view is that, ceteris paribus, an expansion in money supply is associated with a decrease in domestic interest rates, which leads to a depreciation in the domestic currency. Conversely, a tightening of monetary policy leads to an appreciation of the domestic currency. Lewis (1993) utilises VAR modelling to investigate the impact of US monetary shocks on the US dollar exchange rate and finds that a loosening of monetary policy is associated with a depreciating currency. Cushman and Zha (1997) examine the effects of monetary shocks on the Canadian dollar, and again employ the VAR approach to conduct their tests. They conclude that a contraction in the US money supply leads to a depreciation in the Canadian dollar.

There is already literature reporting the causal relationships between the money supply and economic activity in the Euro area (see BIS, 2000). However an investigation into the direct relationships between the money supply and the Euro's exchange rate has so far not been attempted. ${ }^{6}$

To investigate the causal relationships between the movements in the Euro's exchange rate (against the US dollar) and the money supply of the Euro area, monthly data on the Euro's exchange rate $\left(E_{\mathrm{e}}\right)$ and seasonally adjusted M3 are collected from DataStream $^{\mathrm{TM}}$. We use data beginning at January 1997 and ending at August 2001 which provides a sample size of 56 months. ${ }^{7}$ A smaller sample size is considered to be insufficient in order to conduct the analysis. In detecting the causal relationships between the movements of the Euro's exchange rate and the money supply, the optimal VECM models are selected for $\log (\mathrm{M} 3)$ and $\log \left(\mathrm{E}_{\mathrm{e}}\right)$ at $\mathrm{T}=56,57,58,59$ and 60 . To increase the sample size from 57 to 60 we then add a single month sequentially from September 2001 to December 2001, and reestimate the model as we add each observation. To examine stationarity for each series, the augmented Dickey-Fuller (ADF) unit root test is used. The results show that both $\log \mathrm{E}_{\mathrm{e}}$ and $\log \mathrm{M} 3$ are $\mathrm{I}(1)$ processes at $\mathrm{T}=56,57,58$, 59 and $60 .^{8}$ 
Table 1 The VECMs ${ }^{\mathrm{a}, \mathrm{b}}$ selected for detecting the causal relationships between $\mathrm{E}_{\mathrm{e}}$ and M3

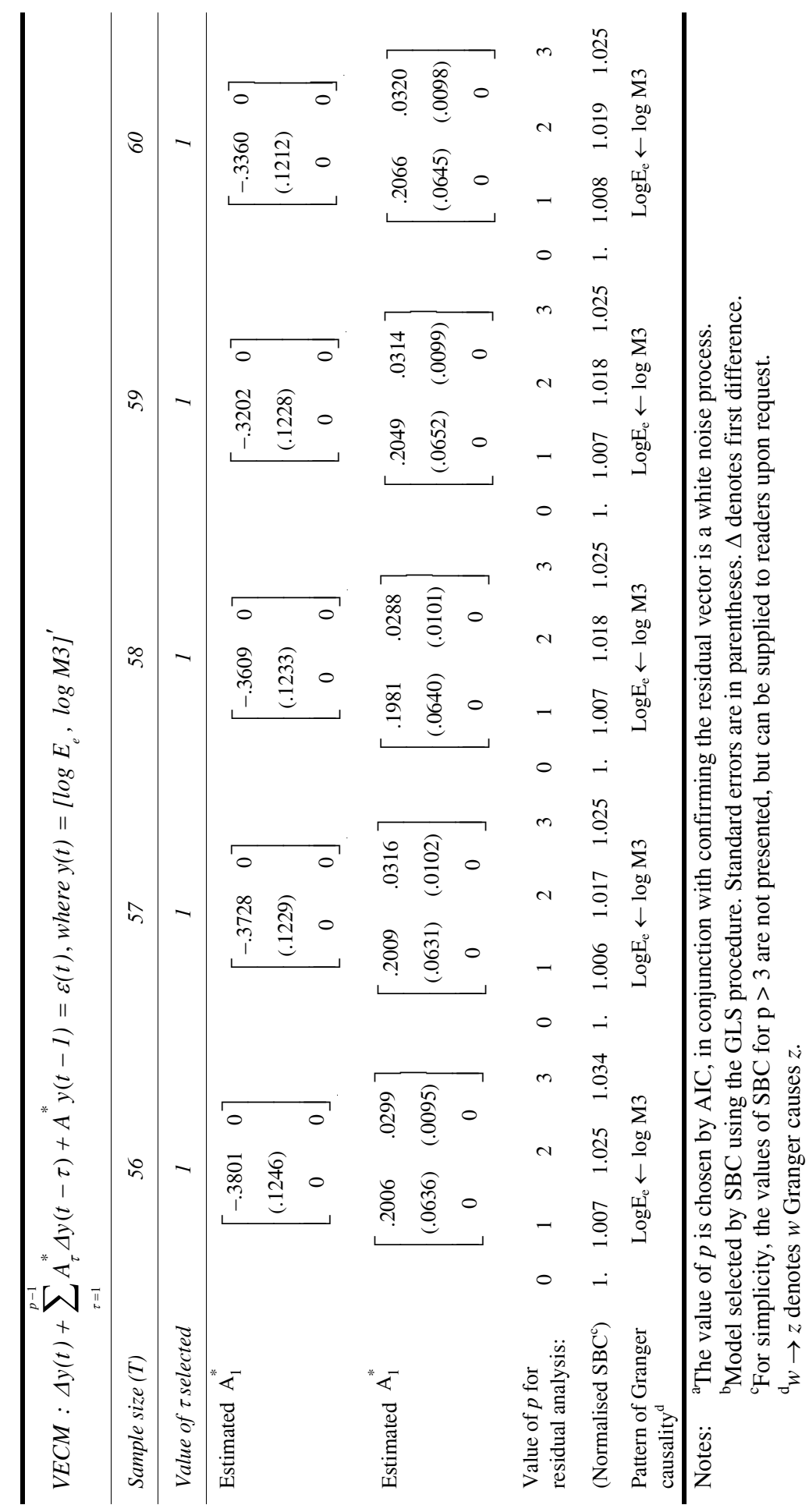


To demonstrate the usefulness of the proposed algorithms in a small sample environment, a maximum order of 12 is selected. We use a maximum lag of 12 because we expect the non-zero coefficients in the autoregressive part to have lag length less than 12, and accept the likelihood is high of a ZNZ patterned lag structure. We also need to keep as many degrees of freedom as possible. This bi-variate system includes coefficient matrices in the VAR part and an impact matrix. The maximum lag of 12 gives us $4^{13}=67108864$ possible candidate models to select the optimal VECM model.

Following the proposed algorithm, the optimal ZNZ patterned VECM models from $\mathrm{T}=56$ to $\mathrm{T}=60$ are chosen using the Schwarz Bayesian Criterion (SBC). ${ }^{9}$ The optimal models selected are estimated using the GLS techniques and are shown in Table $1 .{ }^{10}$ To check the adequacy of each optimal model fit, the strategy suggested in Tiao and Tsay (1989) and Penm et al. (1997) is used, with the proposed Penm and Terrell (1984) algorithm applied to test each residual vector series, using the SBC criterion. ${ }^{11}$ The results in Table 1 support the hypothesis that each residual vector is a white noise process. These optimal models are then used as the benchmark models for analysing the causal relationships. In addition, in conducting the instantaneous causality detection, the algorithm proposed in Penm and Terrell (1984) is also applied to the estimated V of each optimal model. ${ }^{12-13}$

In analysing the causality detected, a patterned VECM which shows Grangercausality from $M 3$ to $E_{e}$, Granger no-causality from $E_{e}$ to $M 3$, and no instantaneous causality between $\mathrm{M} 3$ and $\mathrm{E}_{\mathrm{e}}$ is selected at all times. This outcome confirms that the money supply influences the movements of the Euro over the test period. M3 is detected as a variable, which produces leading information on the Euro's movements. That is, a shock to M3 creates a lagged response in the Euro. These findings are consistent with economic intuition and prior evidence.

\subsection{Purchasing power parity in Japan}

The second application examines Purchasing Power Parity (PPP) using the bilateral exchange rates between the Japanese Yen and the US dollar. The PPP theory states that movements in the exchange rate between two countries' currencies are determined by movements in their relative prices. Formally the PPP condition can be expressed as $E_{t}=P_{t} / P_{t}^{*}$, where $E_{t}$ denotes units of domestic currency per unit of foreign currency, $P_{t}$ domestic price level, and $P_{t}^{*}$ foreign price level.

Recently, cointegration has been widely utilised to test for PPP. Following Engle and Granger (1987), consider an $\mathrm{I}(1)$ system where both $\log \left(\mathrm{E}_{\mathrm{t}}\right)$ and $\log \left(\mathrm{P}_{\mathrm{t}} / \mathrm{P}_{\mathrm{t}}^{*}\right)$ are characterised as integrated of order 1 . If there is a long-term cointegrating relationship between them, that is $\beta^{\prime} \mathrm{X}_{\mathrm{t}}=\left(\beta_{1}, \beta_{2}\right)\left[\log \left(\mathrm{E}_{\mathrm{t}}\right), \log \left(\mathrm{P}_{\mathrm{t}} / \mathrm{P}_{\mathrm{t}}^{*}\right)\right]^{\prime}=\varepsilon_{\mathrm{t}}$ with $\varepsilon_{\mathrm{t}}$ as a stationary process, then PPP holds in the long run. ${ }^{14}$

In contrast to the commonly employed unit-root based tests and full-order VECM modelling, the ZNZ VECM modelling presents a single framework for conducting causality detection and cointegration investigation among the variables involved in the system, and provides estimates of the long-term and dynamic responses. 
Prior research has shown that high-frequency data (for example monthly data) may not reveal evidence of PPP in the long run (see Corbae and Ouliaris, 1998). However when researchers (see Edison, 1987; Kim, 1990) shift to low-frequency data such as an annual series, and use cointegration techniques to test the PPP, empirical evidence usually supports the long run PPP hypothesis. ${ }^{15}$

For the test, monthly averaged data over the period January 1974 to December 2000 for the following three variables are obtained from DataStream ${ }^{\mathrm{TM}}$ :

1 Japanese Yen to US dollar: exchange rate (E) per US dollar

2 Japanese CPI to US CPI: ratio of price levels (P)

$3(1+$ US discount rate $) /(1+$ Japanese discount rate $)$ : interest rate ratio (IR). ${ }^{16}$

The $y$ vector comprises $\log (\mathrm{E}), \log (\mathrm{P})$, as well as $\log (\mathrm{IR})$. The unit root tests indicate that all three variables are I(1). ${ }^{17}$ To select the optimal ZNZ patterned VECM, we start with a maximum lag of 24 to search the optimal subset VECM model. Among the $2^{25}$ possible candidate subset VECM models, the optimal subset VECM selected has a maximum lag of 16. As we use monthly observations VECM modelling is able to accommodate both long-term and dynamic responses including seasonal effects. Thus it is reasonable that the search algorithm has produced a maximum lag of 16 .

Given the framework of this subset VECM, we then select the optimal ZNZ patterned VECM in terms of model selection criteria. ${ }^{18}$ The optimal patterned VECM identified is presented in Table 2.

The presence of the long-term cointegrating relationships shown in Table 2 is consistent with PPP holding within the I(1) system and across the Japanese and US exchange markets. ${ }^{19}$ The selected pattern of the cointegrating vector also demonstrates some interesting findings. In relation to PPP, the positive relation between $\log (\mathrm{E})$ and $\log (\mathrm{P})$ and the positive relation between $\log (\mathrm{E})$ and $\log (\mathrm{IR})$ indicate that an increase in $\mathrm{P}$ or an increase in IR leads to a depreciation of the Yen. This result is consistent with economic intuition. For instance, when the price level in Japan is higher relative to the price level in the USA, the Yen would depreciate in order to retain PPP. Further, when the interest rate in Japan relative to the interest rate in the USA decreases, there is an associated depreciation of the Yen.

In reference to the Granger causal relations among the variables, feedback relations exist between the pair of $\log (\mathrm{P})$ and $\log (\mathrm{IR})$, and the pair of $\log (\mathrm{E})$ and $\log (\mathrm{IR})$. Direct Granger causation exists from $\log (\mathrm{E})$ to $\log (\mathrm{P})$. Although there is no direct Granger causation from $\log (\mathrm{P})$ to $\log (\mathrm{E})$, indirect causation exists from $\log (\mathrm{P})$ to $\log (\mathrm{E})$ via $\log (\mathrm{IR})$. We therefore conclude that a Granger causal relation (directly or indirectly) exists between $\log (\mathrm{E})$ and $\log (\mathrm{P})$. Hence, the feedback within the system is complete and shocks to any one of the variables will be transmitted through the system. In addition, no instantaneous causality is detected among the variables.

Figure 2 shows that all roots detected lie outside the unit circle $(>1)$. This latter finding shows that the selected model has no unit roots or unstable roots. Thus the model is a stable one. Also a strong dynamic structure is found, and cointegrating vectors are identified. Complete causality patterns, including both non-causality and indirect causality are also given. Therefore the model is a powerful one. Also, to check the adequacy of the model fit, the results in Table 2 support the hypothesis that the residual vector is a white noise process. 
Table 2 Monthly sampling - the VECM ${ }^{\mathrm{a}, \mathrm{b}}$ identified for examining PPP in Japan

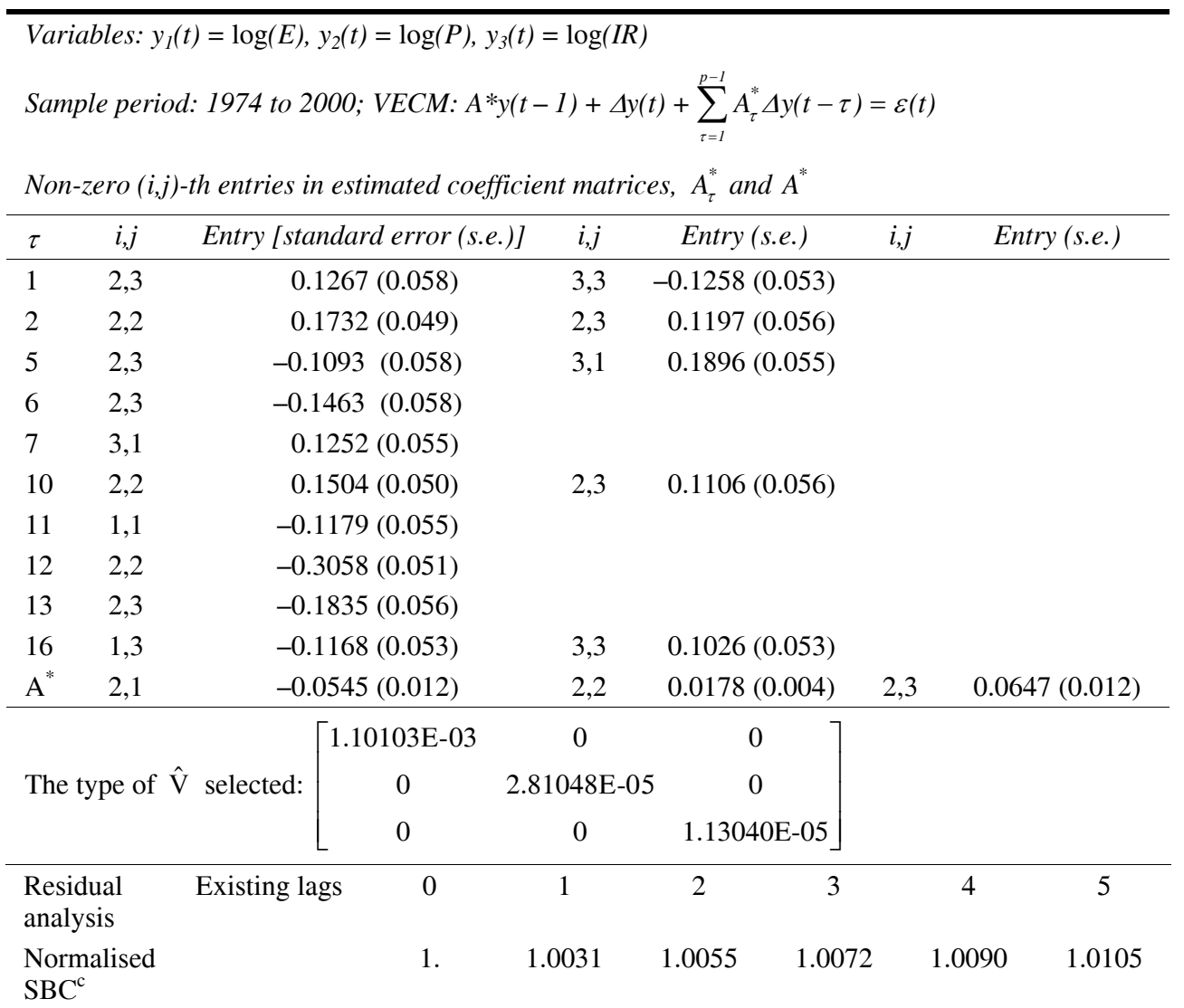

Long-term cointegrating relationship identified: $\log (\mathrm{E})=.3281 \log (\mathrm{P})+1.1853 \log (\mathrm{IR})$

Granger causal pattern recognised: ${ }^{\mathrm{d}}$

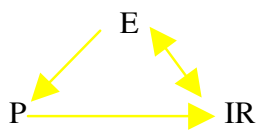

Notes: $\quad{ }^{\mathrm{a}}$ The value of $p$ is chosen by AIC, in conjunction with confirming the residual vector is a white noise process.

${ }^{b}$ Model selected by SBC using the GLS Procedure. Standard errors in parentheses. $\Delta$ denotes first difference.

${ }^{c}$ For simplicity, the values of SBC for $\mathrm{p}>5$ are not presented, but can be supplied to readers upon request. Of note, the SBC criterion is the sum of two terms. The first term is the log of the determinant of the estimated residual variance-covariance matrix, while the second term depends on the number of functionally independent parameters estimated and a term which is $\log$ (sample size)/sample size. In this paper all SBC values computed for the two applications are positive values. No negative values have been obtained. To conserve space and to avoid cluttering we use the normalised SBC values. Since all SBC values are positive in this paper, the smallest normalised SBC is used to determine the lag parameter $p$.

${ }^{\mathrm{d}} x$ Granger-causes $y$ : (Notation : $\mathrm{x} \rightarrow \mathrm{y}$ ); Feedback exists between $x$ and $y$ : (Notation : $\mathrm{x} \leftarrow \rightarrow \mathrm{y}$ ). 
Figure 2 Histogram of roots for the VECM shown in Table 2

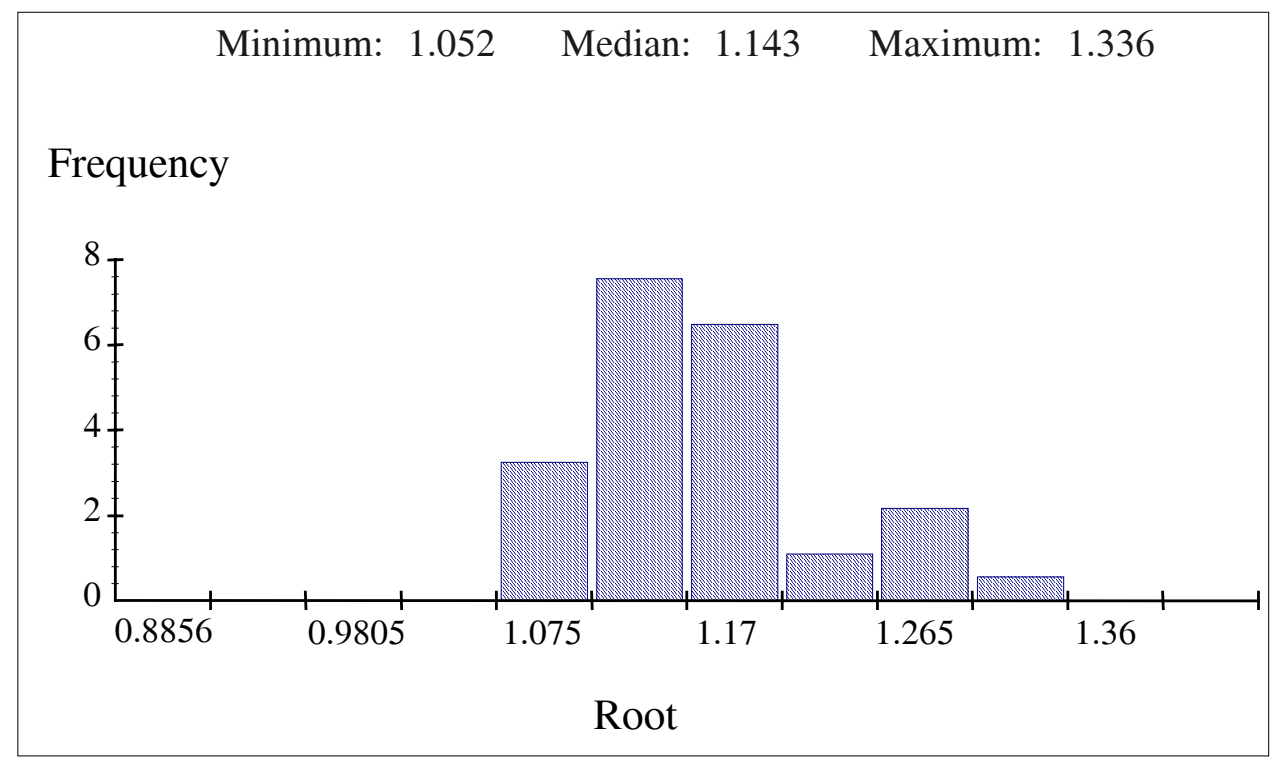

\section{Conclusion}

In this paper, three contributions have been made in the analysis of vector financial time series where causality detection and cointegration investigation are important. First, we have shown that ZNZ patterned VECM modelling not only accommodates long-term and dynamic responses for analysing cointegrating relations, but also provides a single framework for detecting direct and indirect causality among the variables. Compared with full-order VECM modelling, patterned VECM modelling is a more effective means of causality detection and the associated cointegration investigation for time series of integrated order $\mathrm{I}(\mathrm{d})$, where the structure is truly patterned.

Second, the paper shows how, in a limited context, ZNZ patterned VECM modelling can be applied to studying the relationships among financial variables. Specifically, the evidence here shows that money supply (M3) is a source of financial and economic influence on the Euro.

Third, a general outcome of previous studies indicates that long-term PPP may not hold with high-frequency data. In this paper, support for PPP is found using monthly data between Japan and the USA. The findings indicate that both direct and indirect causality exist among prices, interest rates and the exchange rate. This evidence sheds light on the adjustment mechanisms through which PPP is achieved. In addition, it is clear that the proposed ZNZ patterned VECM modelling allows better modelling insights in conducting financial time-series analysis. 


\section{References}

Bank for International Settlements (2000) 70th Annual Report, March.

Brailsford, T.J., Penm, J. and Terrell, R.D. (2006) 'Causality detection on us mutual fund movements using evolutionary subset time-series', International Journal of Services and Standards, Vol. 2, No. 4, pp.368-383.

Chen, W.H., Shih, J.Y. and Wu, S. (2006) 'Comparison of support-vector machines and back propagation neural networks in forecasting the six major Asian stock markets', International Journal of Electronic Finance, Vol. 1, No. 1, pp.49-67.

Cheng, B.S. (1999) 'Beyond the purchasing power parity: testing for cointegration and causality between exchange rates, prices, and interest rates', Journal of International Money and Finance, Vol. 18, pp.911-924.

Chow, G.C. (1983) Econometric Analysis by Control Methods, New York: Wiley.

Christoffersen, P.F. and Diebold, F.X. (1998) 'Cointegration and long-horizon forecasting', Journal of Business and Economic Statistics, Vol. 16, pp.450-458.

Corbae, D. and Ouliaris, S. (1988) 'Cointegration and tests of purchasing power parity', Review of Economics and Statistics, Vol. 70, pp.508-511.

Cushman, D.O. and Zha, T. (1997) 'Identifying monetary policy in a small open economy under flexible exchange rates', Journal of Monetary Economics, Vol. 39, pp.433-448.

Edison, H.J. (1987) 'Purchasing power parity in the long-term: a test of the dollar/pound exchange rate (1890-1978)', Journal of Money, Credit and Banking, Vol. 19, pp.376-387.

Engle, R.F. and Granger, C.W.J. (1987) 'Cointegration and error-correction, representation, estimation and testing', Econometrica, Vol. 55, pp.69-104.

Engle, R.F. and Yoo, B.S. (1987) 'Forecasting and testing in co-integrated system', Journal of Econometrics, Vol. 35, pp.143-159.

European Central Bank (2001) Monthly Bulletin, February.

Granger, C.W.J. (1981) 'Some properties of time series data and their use in econometric model specification', Journal of Econometrics, Vol. 16, pp.121-130.

Hannan, E.J. and Deistler, M. (1988) The Statistical Theory of Linear Systems, New York: John Wiley and Sons.

Hsiao, C. (1982) 'Autoregressive modeling and causal ordering of economic variables', Journal of Economics Dynamics and Control, Vol. 4, pp.243-259.

Johansen, S. (1988) 'Statistical analysis of cointegration vectors', Journal of Economic Dynamics and Control, Vol. 12, pp.231-255.

Johansen, S. (1995) 'A statistical analysis of cointegration for I(2) variables', Econometric Theory, Vol. 11, pp.25-29.

Kumar, S. and Turner, L. (2006) 'Real-world real options: a powerful decision technology tool for managing risk and flexibility in capital investment', International Journal of Electronic Finance, Vol. 1, No. 1, pp.68-93.

Kim, Y. (1990) 'Purchasing power parity in the long run: a cointegration approach', Journal of Money, Credit and Banking, Vol. 22, pp.491-503.

King, R., Plosser, C., Stock, J.H. and Watson, M.W. (1991) 'Stochastic trends and economic fluctuations', American Economic Review, Vol. 81, pp.819-840.

Lee, B.S. (1996) 'Comovements of earnings, dividends, and stock prices', Journal of Empirical Finance, Vol. 3, pp.327-346.

LeSage, J.P. (1990) 'A comparison of the forecasting ability of ECM and VAR models', Review of Economics and Statistics, Vol. 72, pp.664-671.

Lewis, K.K. (1993) 'Are foreign exchange intervention and monetary policy related and does it really matter?', NBER Working paper, No. 4377. 
Lothian, J.R. (1997) 'Multi-country evidence on the behavior of purchasing power parity', Journal of International Money and Finance, Vol. 16, pp.19-35.

McFarland, J.W., McMahon, P.C. and Ngama, Y. (1994) 'Forward exchange rates and expectations during the 1920s: a re-examination of the evidence', Journal of International Money and Finance, Vol. 13, pp.627-636.

Oh, K.Y. (1996) 'Purchasing power parity and unit root tests using panel data', Journal of International Money and Finance, Vol. 15, pp.405-418.

O'Neill, T.J., Penm, J. and Terrell, R.D. (2004) 'The sequential estimation of subset vector autoregressive modeling with a forgetting factor and an intercept variable using the exact window case', International Journal of Theoretical and Applied Finance, Vol. 7, No. 8, pp.1-17.

Penm, J. (2007) 'Asian Rupee for a common electronic financial market of India and the ASEAN region', International Journal of Electronic Finance, Vol. 1, No. 4, pp.473-483.

Penm, J. (2008) 'An innovative kernel-based recursive time-series learning algorithm with applications to improvements of beehive management practices', International Journal of Innovation and Learning, Vol. 5, No. 2, pp.155-169.

Penm, J. and Terrell, R.D. (1984) 'Multivariate subset autoregressive modeling with zero constraints for detecting causality', Journal of Econometrics, Vol. 3, pp.311-330.

Penm, J.H., Penm, J. and Terrell, R.D. (1997) 'The selection of ZNZ patterned cointegrating vectors in error-correction modeling', Econometric Reviews, Vol. 16, pp.281-304.

Refenes, A., Abu-Mustafa, Y., Moody, J. and Weigend, A. (Eds.) (1996) Neural Networks in Financial Engineering, London: World Scientific Publishing Co.

Tiao, G.C. and Tsay, R.S. (1989) 'Model specification in multivariate time-series', Journal of the Royal Statistical Society B, Vol. 51, pp.157-213.

Wong, A., Penm, J. and Service, D. (2007) 'Are mortgage and capital markets integrated in the USA? A study of time-varying cointegration', International Journal of Services Technology and Management, Nos. 4-5, pp.403-420.

\section{Notes}

1 Christoffersen and Diebold (1998) indicate that imposing cointegration on a bivariate system can improve forecasts.

2 Of note, an I(1) system does not contain any fractionally integrated variables.

3 Chow (1983) examines Granger causality in a bivariate time-series model, and discusses the use of zero restrictions to represent causality interaction in different but equivalent model specifications. Chow's models are not set up to separate the dynamic and long-term responses. However, VECM models proposed in this paper accommodate both long-term and dynamic responses.

4 There are two appendices to this paper which are available upon request. Appendix A outlines the algorithm proposed by Penm et al. (1997) for the selection of the optimal VECM. Appendix B describes the use of the Yule-Walker relations for fitting ZNZ patterned VECM models.

5 For more detail, again refer to Penm and Terrell (1984) and Hsiao (1982).

6 Of course, in reality the relationship between the money supply and exchange rate involves other relevant variables, including, but not limited to, international funds flows, consumer prices and interest rate differentials.

7 The Euro was in a preliminary stage prior to 1 January 1999. The currency was an artificial construct comprising a basket - the European currency unit - that was used by the member states of the EU as their internal accounting unit for the currency area of the European 
Monetary System (EMS). The EMS was a managed flexible exchange rate system that defined bands wherein the bilateral exchange rates of the member countries could fluctuate. In this sense the data pre-1999 are not true market-determined rates but rather indicative figures.

8 To preserve journal space, the relevant test results are not presented here but can be supplied on request.

9 The zero entries are determined from the data using the model selection criteria to determine the optimal ZNZ patterned VECM model. Details are provided in the appendices.

10 In a simultaneous equation system GLS estimates are more efficient than OLS estimators, when the regressors in each individual equation are not identical. Since the VECM is a simultaneous equation system, and the ZNZ pattern is extremely unlikely to produce the same regressors in each equation, GLS techniques will be necessary in most cases.

11 In ZNZ patterned time-series modelling Tiao and Tsay (1989) propose an algorithm using the $\operatorname{crit}(\mathrm{m}, \mathrm{j})$ criterion to select the vector autoregressive moving average process with zero entries. After the final model is selected, their algorithm is then applied to the residual series to test whether this series is a vector white noise process.

12 It is useful to reestimate the model parameters using the sample sizes of $\mathrm{T}=56,57,58,59$ and 60. Since we achieved a similar specification for all sample sizes under examination. This supports a constant parameter specification with identical ZNZ patterns showing that our specification results are not changing as we include additional observations.

13 Instantaneous causality indicates the interactions among contemporaneous variables involved in the system (see Chow, 1983).

14 For this case, McFarland et al. (1994) claim that the necessary condition for PPP holds in the long run. If the cointegrating vector is $\beta^{\prime}=(1,-1)$, the necessary and sufficient condition for PPP will hold.

15 Examples of using cointegration techniques to find evidence of PPP include Lothian (1997), and Oh (1996).

16 Consistent with the Fisher equation, the interest rate ratio is expressed in this form and is numerically less variable than the simple ratio of percentage rates. Recently Cheng (1999) has included the interest ratio variable when he conducts PPP testing and causality detection. Cheng's analysis concerns PPP between the USA and Japan using annual data, and he finds evidence supporting PPP in the long run. In order to compare our findings with Cheng's results, the interest ratio variable has been included in the analysis.

17 Since the interest rate ratio has characteristics consistent with an evolutionary process, it is reasonable that this series is $\mathrm{I}(1)$. The unit root tests show that the variable, $(1+$ US discount rate), is $\mathrm{I}(1)$ and so is the variable, $(1+$ Japanese discount rate). In this instance we also find that the ratio of these two variables is $\mathrm{I}(1)$.

18 These model selection criteria are the combination of a measure for in-sample fitting and a scaled penalty for over use of parameters (see Hannan and Deistler, 1988). Thus in-sample fitting results have played a part in the model selection criteria decision making.

19 Cheng's analysis also finds evidence of cointegration among these series. 